\title{
Prospects of Trichoderma in Agriculture-Fundamentals and Applications
}

\author{
Rokozeno Chalie-u* and Shish Ram Jakhar \\ Department of Soil Science and Agricultural Chemistry, JNKVV, \\ Jabalpur (MP)- 482004, India \\ *Corresponding author
}

\section{A B S T R A C T}

\begin{tabular}{|l|}
\hline Ke y w o r d s \\
$\begin{array}{l}\text { Trichoderma, Soil, } \\
\text { Environment, } \\
\text { Disease and growth }\end{array}$ \\
\hline Article Info \\
\hline $\begin{array}{l}\text { Accepted: } \\
\text { 25 May } 2018 \\
\text { Available Online: } \\
\text { 10 June } 2018\end{array}$ \\
\hline
\end{tabular}

Keywords

Trichoderma, Soil, Environment Disease and growth

Accepted:

Available Online:

10 June 2018
The role of microorganisms does not just start with nutrient mineralization, organic matter decomposition and ends with it. There is much more a particular microbe can do in soil and its ecosystem. One of such is Trichoderma, a fungus found in almost all soil ecosystem and a varied environment conditions covering normal soil to harsh conditions as marshy land, desert soil and other degraded environment. With the ill effects of chemical fertilizers becoming more and more obvious and the increase cost of production that follows, chances have to be given to biocontrol agents like Trichoderma, that has multiple usage in agriculture and beyond besides its ability to control disease incidence. Trichoderma are highly interactive in soil and plant roots and its growth is more in acidic condition compared to alkaline. They are the best known for its role in controlling diseases by acting as mycoparasite. Other roles include bioremediation, waste decomposer offering benefits like solubilizing nutrients, promoting plant growth and resistance to stresses, which ultimately leads to enhanced plant growth.

\section{Introduction}

Plant and soil related problems have been with us since the beginning of agriculture affecting the overall production of crops. Although the use of chemical fertilizers and pesticides has made us achieved higher yield, considerable damages has been caused to the environment disturbing its ecological balance, raising concerns of both the environment and human health. Under such circumstances, use of biological methods or agents involving microorganisms comes to rescue and application of such biological agents is attracting researchers from different fields.
One of the most effectively and widely adopted biological agent is the fungus Trichoderma. Trichoderma is a genus of filamentous Ascomycetes fungi that are among the most frequently isolated soil microorganisms; tropical soils contain 101103 culturable propagules per gram (Harman et al., 2004; Etschmann et al., 2015). They are widely distributed all over the world (Domsch et al., 1980), and found in all soils including forest humus layer (Wardle et al., 1993) as well as in agricultural orchard soils (Roiger $e t$ al., 1991) and natural habitats, especially in those containing or consisting of organic matter (Papavizas, 1985). They are highly 
reproductive, ability to increase plant growth, efficient in nutrient utilization and offer plant defense mechanisms. The most useful strains exhibit a characteristic called 'rhizosphere competence', meaning the ability to colonize plant roots and live in association with it. Apart from its role in parasitizing fungi and reducing diseases, Trichoderma species are also used in decomposing waste and organic matter, to remediate polluted soil, in weed control and various other applications in the fields of medical, industries and food. They are reliable, environmental friendly and cost effective.

\section{Taxonomy and evolution of trichoderma}

Trichoderma belongs to the kingdom fungi, division Ascomycota, class Sordariomycetes, order Hypocreales, family Hypocreaceae and genus Trichoderma. To date, at least 1100 Hypocrea (sexual telemorphic stage)/Trichoderma (asexual anamorphic stage) strains have been identified from 75 molecularly characterized species and many new species are being recognized (Druzhinina et al., 2011).

The history of Trichoderma can be date back to 1794 when Persoon first introduced the name Trichoderma. It was until 1927 that Gilman and Abbott recognized four species under the genus Trichoderma. The first move on development of a particular protocol for species identification was made in 1969 (Rifai, 1969; Samuels, 2006). Subsequently, many novel species of Trichoderma were revealed and by 2013, the genus already consists of more than 200 phylogenetically defined species based on rpb2 sequence (Atanasova et al., 2013). Presently, the International Sub commission on Trichoderma lists $104 \quad$ species (http://www.isth.info/biodiversity/index.php) characterized at the molecular level. Although numerous species have been identified, the most important Trichoderma species used in the fields of agriculture, industrial and medical are: Trichoderma hamatum, $T$. viride, $T$. harzianum, T. koningii, T. longibrachiatum, $T$. reesei and $T$. virens.

\section{General characteristics of Trichoderma}

Trichoderma strains have long been recognized as biological agents, for the control of plant diseases and for their ability to increase root growth and development, crop productivity, resistance to abiotic stresses, and uptake and utilization of nutrients. Trichoderma species are ubiquitous in the environment, especially in soils. The optimum temperature of most Trichoderma species is between $25-30^{\circ} \mathrm{C}$. They are strong opportunistic invaders, fast growing, prolific producers of spores and also powerful antibiotic producers even under highly competitive environment for space, nutrients, and light (Schuster and Schmoll, 2010; Montero-Barrientos et al., 2011). Because of their ability to colonize cellulosic materials, they are found in areas where there is decaying plant material and their population increases with more abundant healthy vegetation (Jaklitsch, 2009). This fungus grows easily on media such as potato dextrose agar (PDA), Malt agar (MA), Blakeslee's agar (BLA) and Czapek Dox agar (CDA) (Bissett, 1991). Trichoderma sporulates profusely on most media producing masses of powder, or in a few species produce slimy, green conidia. The green conidia produced are generally diagnostic feature for identification of the genus. They are prolific producers of extracellular proteins, and are best known for their ability to produce enzymes that degrade cellulose and chitin, although they also produce other useful enzymes. They also show a high level of genetic diversity, and can be used to produce a wide range of products of commercial and ecological interest. 


\section{Genetic approaches}

With the advancement in science, there also comes the need to combine genetic approaches in fungal Trichoderma to help achieve strains that performs better than the former. Screening of diverse population of biocontrol agents is an important requirement for developing efficient biocontrol agents. Recent research shows three species been sequenced, namely $T$. reesei, $T$. atroviride and $T$. virens. The smallest genome size $(34 \mathrm{Mb})$ was found in the weakly mycoparasitic $T$. reese $i$ whereas the $T$. virens was found to have the largest genome (38.8 Mb) (Mukherjee, 2011). Highly parasitic Trichoderma species contain numerous genes that encode production of different enzymes and other compounds involve in the attack against other microbes (Druzhinina et al., 2011). Hundreds of genes are found to be involved in the process of biocontrol mechanisms like mycoparasitism, antibiosis, resistance to stresses, competition and production of enzymes (Monte, 2001). These genes from Trichoderma species are identified, cloned to achieve greater promise that offers more resistance to diseases, higher enzymes production.

Protoplast fusion is a technique of genetic modification where two distinct species are fused together to form new species having characteristics of both. The various enzymes produced by Trichoderma which serve in biocontrol can be combined to give out better strain than the individual strain. This is achieved through the process of protoplast fusion. Use of protoplast fusion technique for Trichoderma yielded improved biocontrol action against Fusarium oxysporum, Rhizoctonia solani, Venturia inaequalis, and Cochliobolus miyabeanus (Kumari, 2000). Mutation is another way to enhance biocontrol ability genetically. It is utilized to bring about variability in populations in order to choose the most desirable trait (Kumar, 2013).

\section{Ecological functions}

\section{Root colonization}

Trichoderma species are known to colonize plant roots upon coming in contact with it and forms a symbiotic relationship. The major advantage of this relationship is that root colonization increases root growth and length, ultimately leading to an increase in plant growth and productivity as well. When the root system is colonized, a robust root system is developed improving nutrient and water uptake and also providing protection against pathogenic microorganisms (Harman 2000; Benitez et al., 2004; Contreras-Cornejo 2015). Benitez et al., (2004) claimed that the mechanisms involved in root colonization by Trichoderma species are similar to those in mycorrhizal fungi. There are certain toxic compounds like phytoalexins, flavonoids, terpenoids and phenols elicited by plants upon infection and Trichoderma is said to be resistant to these compounds and hence can colonize root successfully.

\section{Plant growth promotion}

The interaction of Trichoderma with plant has an advantageous effect on plants. Among the many, promotion of plant growth is one of the beneficial traits of Trichoderma species (Shukla et al., 2012). Plant growth promotion by Trichoderma has been observed in several crops. This can be seen in results shown by Harman (2000) that there was an increase of $123 \%$ in soybean yield when inoculated with T. harzianum. In yet another report using 10day-old seedlings of the inbred maize line Mo17 grown from untreated or T-22-treated seeds, an increased in growth of shoot and root was observed (Bj "orkman et al., 1998; Harman et al., 2004). Trichoderma fungi are also capable of producing zeaxanthin and gibberellin, i.e. compounds accelerating seed germination. They induces root branching and 
increase shoot biomass because of cell division, expansion and differentiation by the presence of fungal auxins compound.

\section{Nutrient solubilization}

Nutrient solubilization and plant growth promotion are complimentary to each other. The ability of Trichoderma to increase plant growth involves solubilization of nutrients and making it available for plant uptake. Many Trichoderma strains produce acids, e.g. gluconic, citric, and coumaric acids, causing the release of phosphorus ions and microelements, which subsequently become available to plants (Harman et al., 2004). Trichoderma species like T. harzianum T22 can solubilize various plant nutrients, such as rock phosphate and micronutrients like $\mathrm{Fe}^{3+}$, $\mathrm{Cu}^{2+}, \mathrm{Mn}^{4+}$ and $\mathrm{Zn}$ that can be limiting to plants in certain soils (Altomare et al., 1999).

\section{Resistance to abiotic stresses}

Another yet superstar function of Trichoderma is its ability to offer resistance to abiotic stresses. The effect of $T$. harzianum T-22 been evaluated on the germination of tomato seeds under osmotic stress. Seed treatment with T-22 resulted in faster and more uniform germination compared with untreated seeds at all water deficit levels (Mastouri, Bj “orkman and Harman 2010). Trichoderma are known to produce several secondary metabolites, among which IAA has a key role in saline stress adaptation and is considered to be a new mechanism by which microorganisms induce salt stress tolerance, altering the hormonal pathway (Waqas et al., 2012). (Brotman et al., 2013).

Fig.1 Mode of biocontrol action by Trichoderma

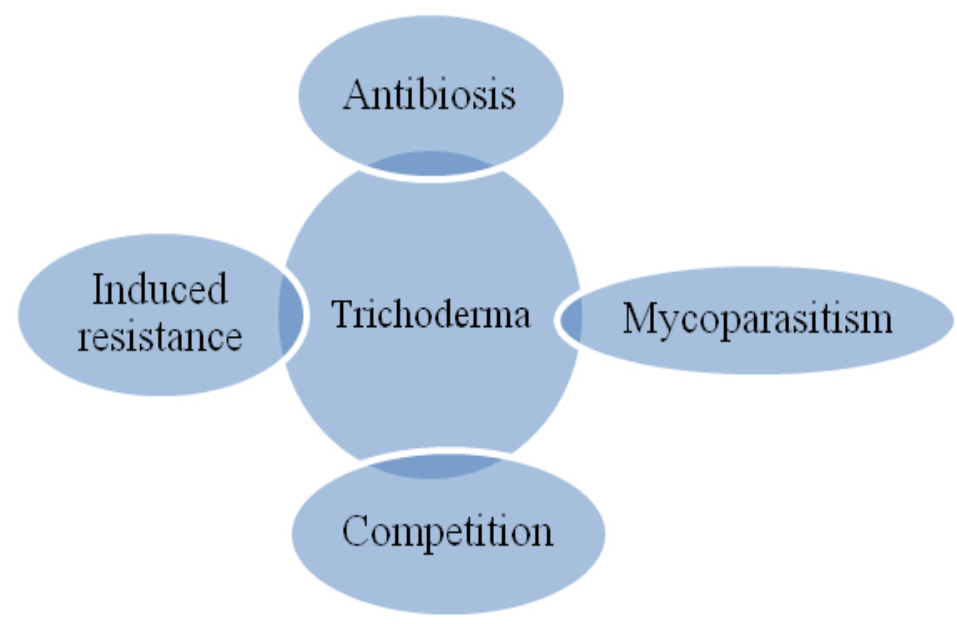

\section{Enzyme production}

One of the most interesting aspects of Trichoderma species lies in its ability to produce a number of enzymes which are involved in different mechanisms of promoting plant growth as well as in reducing disease incidence. Secretion of these enzymes results in the suppression of plant pathogen activities directly and indirectly.
Cell wall degrading enzymes such as chitinases and glucanases produced by Trichoderma are responsible for suppression of the plant pathogen. These enzymes function by breaking down the polysaccharides, chitin, and $\beta$ - glucans that are responsible for the rigidity of fungal cell walls, thereby destroying cell wall integrity (Howell, 2003). 
Trichoderma spp. attach to the host hyphae by coiling, hooks or apressorium-like structures and penetrate the host cell walls by secreting hydrolytic enzymes such as a basic proteinase (Geremia et al., 1993), $\beta$-1,3-glucanase and chitinase (Elad et al., 1993). Chitin, $\beta$-1,3glucan and protein are the main structural components of most fungal cell walls (Peberdy, 1990). This serves as the basis for the suggestion that hydrolytic enzymes produced by Trichoderma spp. play an important role in destruction of plant pathogens (Chet and Baker, 1981).

\section{Prospects of Trichoderma as a biocontrol agent}

The potential use of Trichoderma species as a biocontrol agent was suggested by Weindling in 1932. Estimated proportion of about $90 \%$ of antagonistic fungi used in plant protection is by Trichoderma (Benitez et al., 2004). Most of these biocontrol belongs to the species $T$. harzianum, $T$. viride and $T$. hamatum. The different modes of actions are mycoparasitism, antibiosis, induced resistance and competition.

\section{Mycoparasitism}

Mycoparasitism is an antagonistic interaction where one fungi parasitize the other fungi. The process is a complex one and includes growth of Trichoderma towards the host, recognition of the host, secretion of extra cellular enzymes, penetrations of the hyphae and lysis of the host (Zeilinger et al., 1999). The process of mycoparasitism is under the control of enzymes secretion including $\beta$ - 1,3glucanase and proteases. Upon reaching the host, its hyphae coils around it forming a hook-like structure called appressoria (Elad et $a l .$, 1983). The step consists of the production of cell-wall degrading enzymes (CWDEs) and peptaibols (Howell, 2003), which facilitate both the entry of Trichoderma hyphae into the lumen of the parasitized fungus and the assimilation of the cell-wall content.

\section{Antibiosis}

Antibiosis occurs when one organism excrete compounds which are toxic to the other organisms. The antibiosis occurring during interaction involves low molecular weight diffusible antibiotics produced by Trichoderma that inhibit the growth of antagonistic fungi. The genus Trichoderma produces over 180 secondary metabolites, representing different classes of chemical compounds (Gams and Bisset 1998; Reino et al., 2008). Howell and Stipanovic, in 1983 isolated from $T$. virens and described a new antibiotic called gliovirin that was found to be strongly inhibitory to Pythium ultimum and a Phytophthora species. In tobacco plants, exogenous application of peptaibols activated defense responsive genes and showed reduced susceptibility to Tobacco mosaic virus (Wiest et al., 2002). The combination of hydrolytic enzymes and antibiotics results in a higher level of antagonism than that obtained by either mechanism alone (Monte, 2001). When combinations of antibiotics and hydrolytic enzymes were applied to propagules of $B$. cinerea and $F$. oxysporum, synergism occurred, but it was lower when the enzymes were added after the antibiotics, indicating that cell wall degradation was needed to establish the interaction (Howell, 2003).

\section{Competition}

Competition for space and nutrients always occurs where there microorganism interact and in area where nutrient is deficit. It is one of the causes for the death of many microorganisms. Trichoderma species are generally considered to be aggressive competitors and the ability to compete varied with species (Wardle et al., 1993). Lo et al., (1996) in their study found that a strain of $T$. 
harzianum (T-22) was strongly rhizosphere competent and able to control several plant pathogenic fungi including $R$. solani and it reduced the initial disease severity by as much as $71 \%$ on a variety of crops. Trichoderma also serve as siderophore thus limiting the requirement of iron by other antagonistic fungi, ultimately leading to its death.

\section{Induced resistance}

Induction of resistance in host plant by treatment with Trichoderma species is another biological control mechanism (Howell, 2003). Some Trichoderma strains establish longlasting colonization of plant roots and penetrate into the epidermis. There, they produce or release compounds that induce localized or systemic plant resistance responses (Harman et al., 2004).

The first clear demonstration of induced resistance with $T$. harzianum strain T-39 was given by Bigirimana et al., 1997. The result showed that treated soil made leaves of bean plants resistant to diseases caused by the fungal pathogens such as $B$. cinerea and $C$. lindemuthianum, even though T-39 was applied only on the roots and without any on the foliage.

\section{Trichoderma as a biofertilizer}

Trichoderma can be used for a number of crops as a biofertilizer. Application of Trichoderma results in the promotion of growth, yield and increases nutrient availability. Trichoderma biofertilizers is successfully used for various crops including cucumber, tomatoes, maize, rice, sorghum, soybeans and peppers. They offer multiple benefits over chemical fertilizers like reduces the use of chemicals, reduces pollution from overuse of NPK, improves plant growth and yield, cost effective and eco- friendly.

\section{Bioremediation role of Trichoderma}

Several species are frequently used in the in bioremediation of contaminated soil. Population of several Trichoderma species can grow rapidly because of their naturally resistant ability to many toxic compounds such as fungicides, herbicides, insecticides and phenolic compounds (Chet et al., 1997). Bioremediation is often provided e.g. by $T$. harzianum, which detoxifies phenols, cyanides, and nitrates (Lynch and Moffat, 2005). They play also possess the ability to degrade a wide range of insecticides like organochlorines, organophosphates and carbonates (Harman et al., 2004).

\section{Other applications of Trichoderma}

Trichoderma species are used in several other fields besides the applications mentioned above. They are successfully used in decomposing waste and organic matter and are known to hasten the rate of decomposition in a shorter span. Although not much is known, Trichoderma species are reported to be useful in control of weeds (Heraux et al., 2005). Further applications of Trichoderma includes- in textile industry by the use of cellulase enzymes produced by Trichoderma to soften and condition the textiles. Enzymes produced are also used in paper and pulp industry to reduce lignin content. They are applied in wine making and brewery industries and animal feeds (Galante et al., 1998).

It is concluded that Apart from being widely known and accepted as a successful biocontrol agent, Trichoderma has many different sides to it offering multiple advantageous effects on its usage. They boost germination rate, increases root and shoot length, solubilize nutrients, promote healthy plant growth, act against a wide range of pathogenic fungi. They possess many 
qualities that can be employed in different industries. Taking into account the ill effects of chemical fertilizers, they can be successfully accepted as alternative to chemical fertilizers or in combination with it.

\section{References}

Altomare, C., Norvell, W.A., Bj”orkman, T. and Harman, G.E. 1999. Solubilization of phosphates and micronutrients by the plant-growthpromoting and biocontrol fungus Trichoderma harzianum Rifai 129522. Applied and Environmental Microbiology., 65: 2926-33.

Atanasova, L., Druzhinina, I. S. and Jaklitsch, W.M. 2013. Two hundred Trichoderma species recognized on the basis of molecular phylogeny.Trichoderma: Biology and applications. CABI, Wallingford, pp 10-42.

Benitez, T., Rincon, A.M., Limon, M.C. and Codon, A.C. 2004. Biocontrol mechanisms of Trichoderma strains. International Microbiology., 7: 24960.

Bigirimana, J., Meyer, G. de., Poppe, J., Elad, Y. and Hofte, M. 1997. Induction of systemic resistance on bean (Phaseolus vulgaris) by Trichoderma harzianum. Med. Fac. Landbouww. Univ. Gent 62: 1001-1007.

Bissett, J. 1991. A revision of the genus Trichoderma. II. Infrageneric classification. Canadian Journal of Botany., 69: 2357-2372.

Bj”orkman, T., Blanchard, L.M. and Harman, G.E. 1998. Growth enhancement of shrunken-2 (sh2) sweet corn by Trichoderma harzianum 1295-22: effect of environmental stress. Journal of the American Society for Horticultural Science., 123: 35-40.
Brotman, Y., Landau, U., Cuadros-Inostroza, A., Takayuki, T., Fernie, A.R., Chet, I., Viterbo, A. and Willmitzer, L. 2013. Trichoderma- plant root colonization: escaping early defense response and activation of the antioxidant machinery for saline stress tolerance. PLOS Pathogens 9(4): e1003221

Chet, I., Harman, G. E. and Baker, R. 1981. Trichoderma hamatum: Its hyphal interactions with Rhizoctonia solani and Pythium spp. Microbial Ecology., 7: 29-38.

Chet, I., Inbar, J. and Hadar, I. 1997. Fungal antagonists and mycoparasites. In Wicklow DT, Soderstrom B (eds). The Mycota IV: Environmental and microbial relationships. SpringerVerlag, Berlin. pp 165-184.

Contreras-Cornejo, H.A., L'opez-Bucio, J.S., M'endez-Bravo, A., MaciasRodriquez, L., Ramos-Vega, M., Guevara-Garcia, A.A. and LopezBucio, J. 2015. Mitogen-activated protein kinase 6 and ethylene and auxin signaling pathways are involved in Arabidopsis root-system architecture alterations by Trichoderma atroviride. Molecular Plant Microbe Interactions., 28: 70110.

Domsch, K.H., Gams, W. and Anderson, T.H. 1980. Paecilomyces farinosus. In: Domsch, K.H., Gams, W. and Anderson, T.H. (eds) Compendium of Soil Fungi. Academic Press, London, pp. 527-528.

Druzhinina, I.S., Seidl-Seiboth, V., HerreraEstrella, A., Horwitz, B.A., Kenerley, C.M., Monte, E., Mukherjee, P.K., Zeilinger, S., Grigoriev, I.V. and Kubicek, C.P. 2011. Trichoderma: the genomics of opportunistic success. Nature Reviews Microbiology., 16: 749-759. 
Elad, Y., Zimand, G., Zaqs, Y., Zuriel, S. and Chet, I. 1993. Use of Trichoderma harzianum in combination or alternation with fungicides to control cucumber grey mould (Botrytis cinerea) under commercial greenhouse conditions. Plant Pathology., 42: 324-332.

Etschmann, M.M., Huth, I., Walisko, R., Schuster, J., Krull, R., Holtmann, D., Wiltmann, C. and Schrader, J. 2015. Improving 2- phenylethanol and 6pentyl- $\alpha$-pyrone production with fungi by microparticle-enhanced cultivation (MPEC). Yeast., 32(1): 145-57.

Galante, Y.M., De Conti, A. and Monteverdi, R. 1998. Application of Trichoderma enzymes in the textile industry. p. 311- 326. In: "Trichoderma and Gliocladium"(G.E. Harman, C.P. Kubicek, eds.), Taylor \& Francis, London, UK, 393 pp

Gams, W. and Bisset, J. 1998. Morphology and identification of Trichoderma. p. 3-34. In: "Trichoderma and Gliocladium" (G.E. Harman, C.P. Kubicek, eds.). Taylor \& Francis, London, UK, 393 pp

Harman, G.E. 2000. Myths and dogmas of biocontrol. Changes in perceptions derived from research on Trichoderma harzianum T-22. Plant Disease., 84: 377-93.

Harman, G.E., Howell, C.R., Viterbo, A., Chet, I. and Lorito, M. 2004. Trichoderma species- opportunistic, a virulent plant symbiosis. Nature Reviews Microbiology., 2(1): 43-56.

Heraux, F.M.G., Hallett, S.G., Ragothama, K.G. and Weller, S.C. 2005. Composted chicken manure as a medium for the production and delivery of Trichoderma virens for weed control. Horticulture Science., 40(5): 1394-1397.
Howell, C.R. 2003. Mechanisms employed by Trichoderma species in the biological control of plant diseases: the history and evolution of current concepts. Plant Disease., 87: 4-10.

Howell, C.R. and Stipanovic, R.D. 1983. Gliovirin, a new antibiotic from Gliocladium virens and its role in the biological control of Pythium ultimum. Canadian Journal of Microbiology., 29: 321-324.

Jaklitsch, W.M. 2009. European species of Hypocrea Part I. The green-spored species. Studies in Mycology., 63: 191.

Kumar, S. 2013. Trichoderma: A biological weapon for managing plant diseases and promoting sustainability. International Journal of Agricultural Sciences and Veterinary Medicine., 1(3): 106-121.

Kumari, D. 2000. In: Proceeding of Indian Phytopathological Society; Golden Jubilee. International Conference on Integrated Plant Disease Management for Sustainable Agriculture, p. 851

Lynch, J.M. and Moffat, A.J. 2005. Bioremediation - prospects for the future application of innovative applied biological research. Annals of Applied Biology., 146 (2): 217-221.

Mastouri, F., Bj “orkman, T. and Harman, G.E. 2010. Seed treatment with Trichoderma harzianum alleviates biotic, abiotic, and physiological stresses in germinating seeds and seedlings. Phytopathology., 100: 1213-21.

Monte, E. 2001. Understanding Trichoderma: between biotechnology and microbial ecology. International Microbiology., 4: 1-41.

Montero-Barrientos, M., Hermosa, R., Cardoza, R.E., Gutiérrez, S. and Monte, E. 2011. Functional analysis of the Trichoderma harzianum noxl 
gene, encoding an NADPH oxidase, relates production of reactive oxygen species to specific biocontrol activity against Pythium ultimum. Applied and Environmental Microbiology., 77: 3009-3016.

Mukherjee, P.K. 2011. Genomics of biological control - whole genome sequencing of two mycoparasitic Trichoderma spp. Current Science., 101(3): 268.

Papavizas, G.C. 1985. Trichoderma and Gliocladium. Biology, ecology and potential for biocontrol. Annual Review of Phytopathology., 72: 126132.

Peberdy, J.F. 1990. Fungal cell walls- a review. In: Biochemistry of cell walls and membranes in fungi, pp 5-30.

Reino, J.L., Guerrero, R.F., Hernandez-Galan R. and Collado, I.G. 2008. Secondary metabolites from species of the biocontrol agent Trichoderma. Phytochemistry Reviews., 7(1): 89123.

Rifai, M.A. 1969. A revision of the genus Trichoderma. Mycological Papers., 116: 1-56.

Samuels, G.J., Dodd, S., Lu, B.S., Petrini, O., Schroers, H.J. and Druzhinina, I.S. 2006. The Trichoderma koningii aggregate species. Studies in Mycology., 56: 67-133.

Schuster, A. and Schmoll, M. 2010. Biology and biotechnology of Trichoderma.
Applied Microbiology and Biotechnology., 87: 787-799.

Shukla, N., Awasthi, R.P., Rawat, L. and Kumar, J. 2012. Biochemical and physiological responses of rice (Oryza sativa L.) as influenced by Trichoderma harzianum under drought stress. Plant Physiology and Biochemistry., 54: 78-88.

Waqas, M., Khan, A.L., Kamran, M., Hamayun, M., Kang, S.M., Kim, Y.H. and Lee, I.J. 2012. Endophytic fungi produce gibberellins and indoleacetic acid and promotes host-plant growth during stress. Molecules., 17(9): 10754-73.

Wardle, D.A., Nicholson, K.S. and Rahman, A. 1993. Influence of herbicide applications on the decomposition, microbial biomass and microbial activity of pasture shoot and root litter. New Zealand Journal of Agricultural Research., 37(1): 29-39.

Wiest, A., Grzegorski, D. and Xu, B. 2002. Identification of peptaibols from Trichoderma virens and cloning of a peptaibol synthetase. Journal of Biological Chemistry., 277: 2086220868.

Zeilinger, S., Galhaup, C., Payer, K., Woo, S.L., Mach, R.L., Fekete, C., Lorito, M. and Kubicek, C.P. 1999. Chitinase gene expression during mycoparasitic interaction of Trichoderma harzianum with its host. Fungal Genetics and Biology., 26: 131-140.

\section{How to cite this article:}

Rokozeno Chalie-u and Shish Ram Jakhar. 2018. Prospects of Trichoderma in AgricultureFundamentals and Applications. Int.J.Curr.Microbiol.App.Sci. 7(06): 3519-3527. doi: https://doi.org/10.20546/ijcmas.2018.706.413 